\title{
Three intragenic suppressors of a GTPase-deficient allele of GNAS associated with McCune-Albright syndrome
}

Kyle Turcic, Raquel Tobar-Rubin, Daniela Janevska, Julie Carroll, Eraj Din, Rebecca Alvarez, Jennifer Haick and Robin Pals-Rylaarsdam
Correspondence should be addressed to R Pals-Rylaarsdam Email

rrylaarsdam@ben.edu

\begin{abstract}
Gain-of-function mutations in heterotrimeric G-protein $\alpha$ subunits are associated with a variety of human diseases. McCune-Albright syndrome (MAS) is caused by mutations in GNAS, the gene encoding Gs. Alterations at Arg201 significantly reduce the GTPase activity of the protein, rendering it constitutively active. In this study, we have constructed a library of random mutations in a constitutively active yeast GPA1 gene carrying a mutation homologous to the McCune-Albright allele (Arg297His). Intragenic suppressors found at sites with homology to the human Gs protein were tested for their ability to suppress the constitutive activity of an Arg201His mutation in Gs. Three intragenic suppressors, at Phe142, Arg231, and Leu266, were able to suppress elevated basal cAMP responses caused by Arg201His when expressed in HEK293 cells. A range of amino acid substitutions was introduced at each of these sites to investigate the chemical requirements for intragenic suppression. The ability of Gs proteins carrying the suppressor mutations alone to mediate receptor-induced CAMP production was measured. These results offer potential sites on Gs that could serve as drug targets for MAS therapies.
\end{abstract}
Key Words
- McCune-Albright syndrome
- G-protein
- cAMP
- suppressor mutation

Journal of Molecular Endocrinology (2014) 52, 321-331

\section{Introduction}

McCune-Albright syndrome (MAS) was first described in the 1930s as a trio of associated symptoms which included café-au-lait skin hyperpigmentation, precocious puberty, and polyostotic fibrous dysplasia of bone (McCune 1936, Albright et al. 1937). A wide variety of hyperfunctioning endocrine disorders may accompany the classic triad of symptoms, including growth hormone excess, renal phosphate wasting, and Cushing's syndrome (Dumitrescu $\&$ Collins 2008). This widely varied disease is caused by mosaicism for mutations in GNAS, the gene encoding the Gs $\alpha$ subunit of heterotrimeric G-proteins (Gs; Weinstein et al. 1991). Substitution of arginine 201 with another amino acid reduces GTP hydrolysis, causing constitutive activity of the protein and its signaling pathways. Histidine and cysteine substitutions are most common (Weinstein et al. 1991, Schwindinger et al. 1992, Lumbroso et al. 2004), although serine (Candeliere et al. 1997) and glycine (Riminucci et al. 1999) have also been found at codon 201 in MAS isolates.

The endocrine disorders associated with MAS are managed with drugs. For example, the full onset of puberty in MAS patients is delayed until the patient

Published by Bioscientifica Ltd 
approaches a normal age for puberty by using aromatase inhibitors (Feuillan et al. 2007) and/or tamoxifen (Eugster et al. 2003). Fibrous dysplasia often requires repeated surgeries for repair of broken or deformed long bones, or for correction of facial deformities (Collins 2006, Stanton et al. 2012). Clinical trials using bisphosphonates showed a reduction in bone pain (Liens et al. 1994), but no effectiveness in preventing the spread or development of fibrous lesions in children with MAS (Plotkin et al. 2003, Chan \& Zacharin 2006). Clearly, more effective therapies for the bone dysplasias would benefit MAS patients.

One experimental approach to identify targets for rational drug design is to identify intragenic suppressors of mutations associated with a disease, and to analyze the suppressors to gain structural information about the potential drug target. The yeast Saccharomyces cerevisiae is a powerful genetic system for approaching the identification of suppressor mutations, and in particular suppressors of activating mutations in $\mathrm{G} \alpha$ subunits (Apanovitch et al. 1998, Ooms et al. 2006). A great deal is known about the structure of Gs, which aids in the interpretation of the suppressor mutations and their potential as drug targets (Sunahara et al. 1997, Tesmer et al. 1997, Rasmussen et al. 2011). Our laboratory previously undertook a pilot study which randomly mutated a constitutively active allele of GPA1 to search for intragenic suppressors of R297H, homologous to the MAS mutation in Gs. The study identified one site for intragenic suppression, located in the GTP-binding site of the G-protein (Ooms et al. 2006). This report describes a full-scale screen for more intragenic suppressors of constitutively active human Gs, and demonstrates three unique locations on the protein that can reverse the constitutive activity: a residue in the helical domain, one within Switch II, and one that interacts with residues of Switch III.

\section{Materials and methods}

\section{Yeast strains and plasmids}

RM20 (Medici et al. 1997) was a gift from Gianfranco

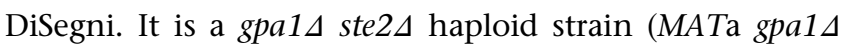
ste2A fus1::FUS1-lacZ[TRP1] ura3/52 trp1 ade2-1 his3-11,5 leu2-3,112) containing the plasmid pYS212 $(2 \mu-U R A 3-T P I$ promoter; R\&D Systems, Minneapolis, MN, USA) carrying the GPA1 gene. The gpa 1 deletion in this strain is deleted for the $0.84 \mathrm{~kb}$ HindIII-SphI fragment of the coding region. The WT yeast strain MHY500 (MATa his3- 4200 , leu2-3,112 ura352 lys2-801 trp1-1; Chen et al. 1993) came from Mark Hochstrasser's Laboratory, who also supplied plasmid
p413GPD (CEN, HIS3, GPD promoters; Mumberg et al. 1995), used to express an EcoRI fragment encoding GPA1 or its mutated allele $R 297 \mathrm{H}$ in yeast cells. The GPA1 alleles were engineered to contain restriction sites for $\mathrm{NcoI}$ at nucleotide 151 and HpaI at nucleotide 1620 (Ooms et al. 2006).

\section{Yeast culture}

YPD-rich yeast medium contains $1 \%$ yeast extract, $2 \%$ BactoPeptone, and $1 \%$ glucose. SD dropout medium contains $0.67 \%$ yeast nitrogen base without amino acids, $1 \%$ glucose, supplemented with the appropriate amino acids, adenine, and uracil. Fluoro-orotic acid (FOA) plates are SD-His dropout plates supplemented with $0.2 \mathrm{mg} / \mathrm{ml}$ uracil and 1\% 5-FOA. All yeast incubations were carried out at $30^{\circ} \mathrm{C}$.

\section{Library construction}

ACGT, Inc. (Wheeling, IL, USA) constructed a library of random mutations in the $S$. cerevisiae GPA1 gene using degenerate PCR. Plasmid p413GPD-GPA1 (R297H) was used as the template for a PCR using the Diversity PCR Random Mutagenesis Kit (Clontech) with $8 \mathrm{mM} \mathrm{MnSO}_{4}, 2 \mathrm{mM}$ dGTP, and $10 \mathrm{mM}$ of each primer (forward, 5'-CACATCATAATCCATGGGTGTATAAATTGATA- $3^{\prime}$ and reverse, $5^{\prime}$-CTAAACACTACGTTAACTATACAGTTCCTTC-3') and $10 \mathrm{ng} / \mathrm{\mu l}$ template DNA. Cycling conditions were $94^{\circ} \mathrm{C}$ for $30 \mathrm{~s}$, then 25 cycles of $94^{\circ} \mathrm{C}$ for $30 \mathrm{~s}$, and $68^{\circ} \mathrm{C}$ for $90 \mathrm{~s}$. The cycle ended with $68^{\circ} \mathrm{C}$ for $1 \mathrm{~min}$ and a $4{ }^{\circ} \mathrm{C}$ soak. The amplified PCR product was separated on a $0.8 \%$ agarose gel and showed a single band at the expected $1.4 \mathrm{~kb}$. The product was then ligated into the pGEM-T Easy Vector (Promega) and transformed into Top 10 chemically competent cells (ACGT, Inc.). The transformed cells were spread onto Luria broth (LB) plates supplemented with ampicillin and X-gal and grown overnight. Plasmid DNA was isolated from 39 clones using the QIAprep Spin Miniprep Kit (Qiagen). The insert DNA was sequenced from both strands using the following primers in addition to the M13-F and M13-R universal primers: GPA1_F1, 5'-GAGACACTGACAGAGATGCTG-3'; GPA1-F2, 5'-TCGAAGGAATTACAGCAGTTT-3'; GPA1-R1, 5'-ACCTTGAATTTGGACGAGC-3'; and GPA1-G2, 5'-CAGCATCT-CTGTCAGTGTCAC-3'. Sequence data from both strands was aligned and a consensus sequence generated. The sequence of each mutant clone was compared with the reference sequence to determine the number of amino acid changes per clone. Of the 39 clones, 12 exhibited no changes, 22 clones exhibited one to three amino acid changes, and five

Published by Bioscientifica Ltd. 
exhibited four to seven amino acid changes. Thirteen large $(150 \mathrm{~mm})$ plates with $\sim 600$ clones/plate were delivered from ACGT, Inc. These colonies were pooled, and the plasmid DNA was purified directly from the colonies without outgrowth using an E.Z.N.A. Plasmid Maxi Kit from Omega Biotek (Norcross, GA, USA). The mutated GPA1 was excised from pGEM-T using NcoI and HpaI, subcloned into pRS413GPD-GPA1, and transformed into NEB 5-alpha Escherichia coli. Approximately, 55000 colonies were pooled, grown in $500 \mathrm{ml} \mathrm{LB} /$ ampicillin for $6 \mathrm{~h}$ at $37^{\circ} \mathrm{C}$ with shaking, and then either frozen back as library stocks or used in a plasmid maxi-prep for yeast transformation. Since this expression vector library was derived from 7800 unique clones, we estimate that each clone is represented seven times in our library, and that the expression library, like the pGEM collection, has only $70 \%$ of its clones with amino acid substitutions.

\section{Library screen}

Yeast were transformed using the Frozen-EZ Yeast Transformation II Kit (Zymo Research, Irvine, CA, USA) and grown on SD-His plates to select for uptake of the library plasmid. Colonies were replica plated to FOA plates, which selected for loss of the URA3-marked plasmid carrying the WT GPA1 allele. Growth of yeast on FOA was followed for 4-6 days. FOA-resistant clones were grown overnight in SD-His liquid medium, the plasmids isolated using the Zymoprep Yeast Plasmid MiniprepII Kit (Zymo Research, Irvine, CA, USA), and then transformed into NEB 5-alpha high efficiency competent E. coli (New England Biolabs, Ipswich, MA, USA). Plasmids were purified from E. coli using the Wizard Plus SV Minipreps DNA Purification System (Promega), re-transformed into RM20 yeast plated on SD-His medium. Colonies from these transformations were patched onto FOA plates to retest for plasmid-dependent FOA resistance. Plasmids that supported RM20 growth on FOA at this point were sequenced (ACGT, Inc.) by the same primers used in the mutagenic PCRs.

\section{Site-directed mutagenesis}

Site-directed mutagenesis of pCDNA3.1 $+\mathrm{GNAS}_{\mathrm{L}}$ was carried out using the Agilent Quick-Change XL Mutagenesis Kit (Agilent, Santa Clara, CA, USA). Sense primer sequences for all mutagenesis reactions are shown in Supplementary Table 1 , see section on supplementary data given at the end of this article. Antisense primers were the exact complement of the sequences above. Primers were synthesized by Life Technologies. Each mutagenic primer also introduced a new restriction endonuclease site into the sequence while changing the amino acid for only the mutated site. Miniprep DNA was digested with the appropriate restriction enzyme(s) and analyzed by agarose gel electrophoresis. All mutagenesis was confirmed by dideoxy sequencing in both directions performed by ACGT, Inc.

\section{Mammalian cell culture}

HEK293 cells (ATCC, Manassas, VA, USA) passages 5-17 were maintained in DMEM supplemented with $10 \% \mathrm{v} / \mathrm{v}$ fetal bovine serum, $1 \% \mathrm{v} / \mathrm{v}$ penicillin-streptomycin, and $1.25 \mathrm{mg} / \mathrm{ml}$ amphotericin $\mathrm{B}$ at $37^{\circ} \mathrm{C}$ in a humidified $5 \%$ $\mathrm{CO}_{2}$ incubator. All cell culture reagents were purchased from Life Technologies.

\section{Transfection}

Typically, $60 \mathrm{~mm}$ plates at $50-60 \%$ confluence were transfected with plasmid DNA using JetPRIME reagent (Polyplus-Transfection, Inc., New York, NY, USA). Up to $5 \mathrm{ml}$ of media covered each plate, and cells were transfected in a total volume of $400 \mu \mathrm{l}$ containing plasmid, $10 \mu \mathrm{l}$ JetPRIME reagent, and the remaining volume JetPRIME buffer. The transfection mixture was dripped directly onto the culture medium, and no refeeding occurred. $24 \mathrm{~h}$ post-transfection, the cells were replated for parallel western blot and signaling assays. Assays for protein expression and second-messenger production were carried out $48 \mathrm{~h}$ post-transfection.

\section{CAMP assays}

The cells were replated $24 \mathrm{~h}$ post-transfection by trypsinization followed by resuspension of the cells in $7 \mathrm{ml}$ of culture medium. $100 \mu \mathrm{l}$ of cells were plated in each of 16 wells of a 96-well culture plate. The remaining cells were allowed to reattach to the $60 \mathrm{~mm}$ culture dish. $48 \mathrm{~h}$ post-transfection, the culture medium was removed, and the cells were exposed to $100 \mu \mathrm{l}$ of varying doses of human chorionic gonadotropin (hCG) or forskolin $(1 \mu \mathrm{M})$ in serum-free DMEM supplemented with $1 \mathrm{mM}$ 3-isobutyl-1-methylxanthine. Following $15 \mathrm{~min}$ of drug treatment at $37^{\circ} \mathrm{C}$, cells were lysed by adding $100 \mu \mathrm{l} 0.2 \mathrm{M} \mathrm{HCl}$. Lysates were frozen at $-20^{\circ} \mathrm{C}$ until protein expression was verified by western blot. Levels of cAMP in the lysates were assayed using a Direct cAMP ELISA Kit (Enzo Life Sciences, Plymouth Meeting, PA, USA) and reported as a percentage of the maximal forskolinstimulated cAMP levels to control for differences in transfection efficiency from experiment to experiment.

Published by Bioscientifica Ltd. 


\section{Western blot}

Whole-cell lysates of transfected cells were prepared by removing the transfected cells from the culture plate in PBS, pelleting the cells with a low-speed centrifuge, and lysing the pellet directly with $100 \mu$ of Lammeli sample buffer in boiling water for $2 \mathrm{~min}$. Proteins were sonicated at 50\% power in a Misonix XL-2000 sonicator for 2-15 s exposures, spun in at $16000 \boldsymbol{g}$ in a microcentrifuge, and then analyzed by western blot immediately or stored in a $-20{ }^{\circ} \mathrm{C}$ freezer until analysis. $20 \mu \mathrm{l}$ of cell lysate was applied to each well of 4-20\% Tris-tricine gradient gel (Expedeon, San Diego, CA, USA), and proteins were separated by electrophoresis and transferred to nitrocellulose. Following 30 min of blocking with LI-COR blocking buffer (LI-COR Biosciences, Lincoln, NE, USA), mouse anti-human Gas MAB12 (Santa Cruz Biotechnology) was diluted 1:2000 in LI-COR blocking buffer and incubated with the membrane for $1-2 \mathrm{~h}$ at room temperature or overnight at $4{ }^{\circ} \mathrm{C}$ with rocking. The membrane was washed five times for $5 \mathrm{~min}$ each with $\mathrm{PBS}$, and then incubated $1-2 \mathrm{~h}$ at room temperature or overnight at $4{ }^{\circ} \mathrm{C}$ with rocking with a 1:10 000 dilution of IRDye $800 \mathrm{CW}$ Goat anti-Mouse IgG (LI-COR Biosciences). The membranes were washed five times for 5 min each in PBS before detection. The blots were imaged with a LI-COR Odyssey Fc for infrared detection of the reactive bands.

\section{Statistical analysis and curve fitting}

GraphPad Prism (GraphPad Software, LaJolla, CA, USA) was used for curve fitting and calculation of $\mathrm{EC}_{50}$ values. Assays for basal and receptor-stimulated cAMP were analyzed by ANOVA followed by Fisher's least significant difference analysis when the ANOVA indicated evidence of a difference among the means.

\section{Results}

Our goal in these experiments was to identify secondary mutations in Gs that can compensate for, or suppress, the constitutive activity of the $R 201 H$ mutation associated with MAS. We desgined a yeast system where the yeast $\alpha$ subunit Gpa1 carried the homologous mutation, $R 297 H$, along with a library of other random mutations in the gene. Yeast cell division is arrested upon release of $\beta \gamma$ from the Gpa1 $\alpha$ subunit; thus, cells carrying only a constitutively active Gpa1-like $R 297 H$ undergo cellcycle arrest. The cells were maintained in a dividing state by providing a second WT copy of Gpa1 on a
URA3-marked plasmid. Transfer to 5-FOA plates selected for loss of the WT plasmid, as Ura3 metabolizes 5-FOA to a toxin. The remaining GPA1 allele supported colony formation only if the random mutations reversed the constitutive activity of $\mathrm{R} 297 \mathrm{H}$, allowing binding to $\beta \gamma$ and cell cycle progression (Ooms et al. 2006). Plasmids were isolated from 166 colonies and the GPA1 coding region was sequenced in its entirety. Mutations that reverted histidine back to arginine and that were not homologous to the human Gs were not analyzed further.

Twelve of the unique mutations that suppressed the constitutive activity of GPA1-R297H were located at sites
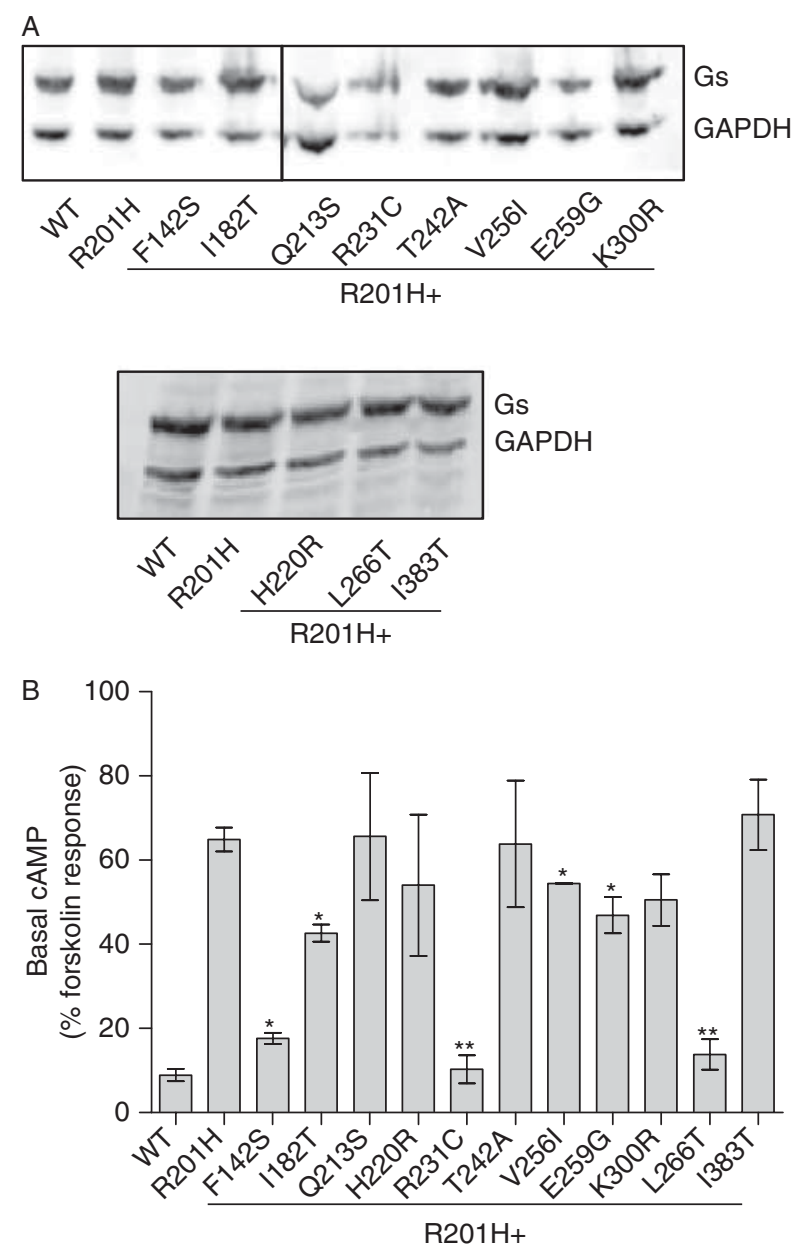

Figure 1

Basal cAMP levels in cells transfected with the suppressors or Arg $\rightarrow$ His mutations originally identified in a yeast screen. (A) Immunoblot of lysates from cells transfected with the indicated alleles of Gs probed for Gs and GAPDH. (B) Basal CAMP levels from cells transiently transfected with $5 \mu \mathrm{g}$ of plasmid encoding the indicated alleles of Gs. Bars represent the mean \pm s.E.M. for three to four independent experiments, each performed in duplicate. * Significantly lower than R201H basal CAMP, $P<0.05$ and **not significantly different from WT basal CAMP, $P>0.05$. 
A

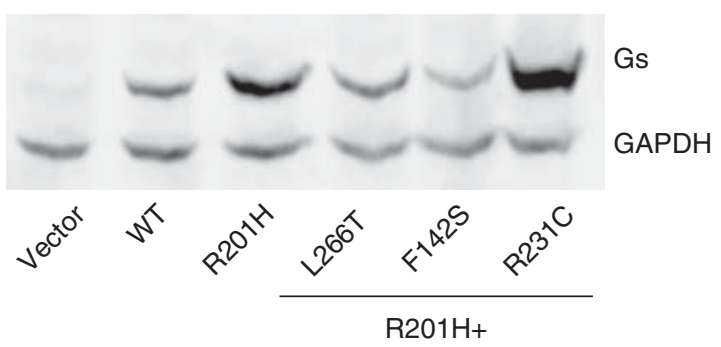

B
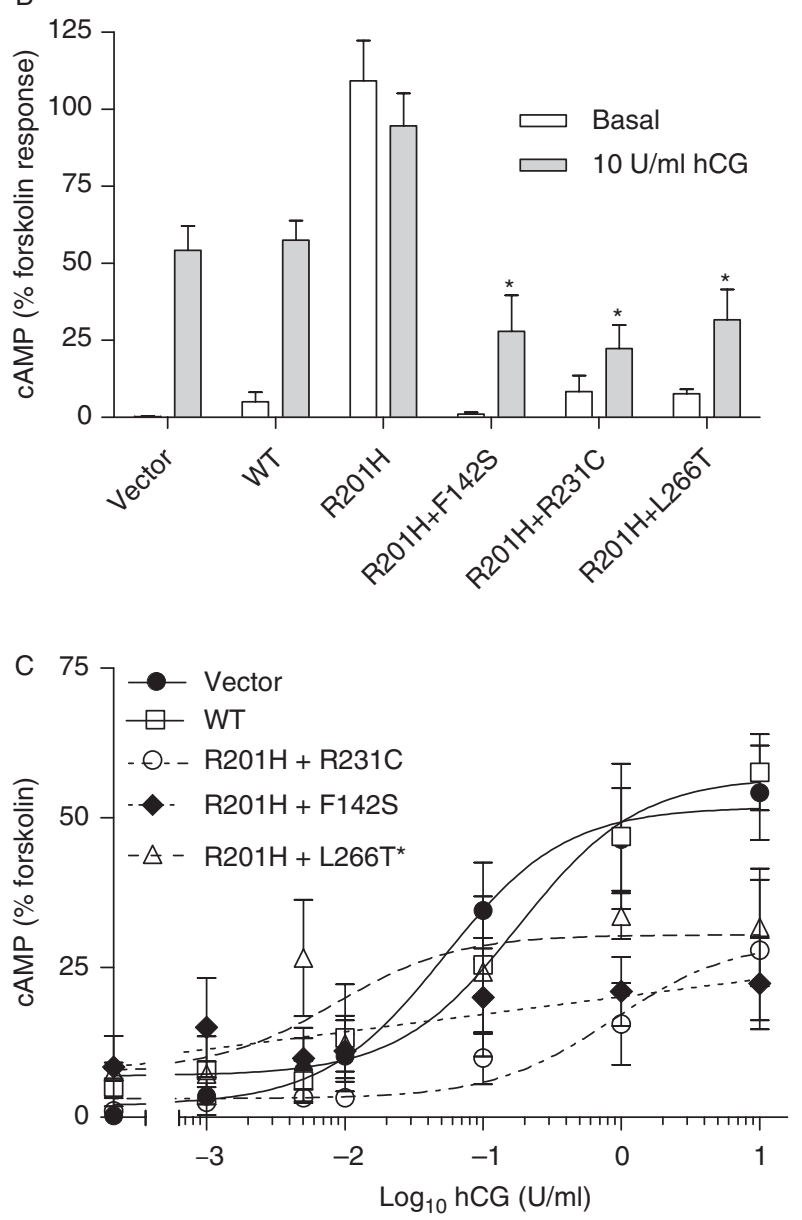

Figure 2

Basal and hormone-stimulated cAMP production in cells expressing intragenic suppressors of R201H. (A) Immunoblot of lysates from cells transfected with the indicated alleles of Gs probed for Gs and GAPDH. (B) Basal and maximally-stimulated CAMP levels from (C). Data are the mean \pm S.E.M. for three independent experiments, each performed in duplicate. *Statistically lower than WT hCG-stimulated levels, $P<0.05$. (C) Dose-response curves for cAMP production in cells cotransfected with the human luteinizing hormone receptor (LHR) and the indicated alleles of Gs. Filled circles, vector; open squares, WT Gs; open circles, R201H/R231C; filled diamond, R201H/F142S; and open triangle, R201H/L266T. Points represent the mean \pm s.E.M. for three independent experiments, each performed in duplicate. conserved with the human Gs protein. Site directed mutagenesis was used to introduce these 12 mutations into the human GNAS cDNA which also carried the MAS R201H mutation. Eleven of these mutant isoforms were successfully expressed in HEK293 cells at levels similar to WT and the $R 201 H$ mutant (Fig. 1a); substitution of H220 with an asparagine residue consistently produced no protein detectable by western blot. Levels of basal cAMP in transfected cells were measured and reported as a percent of the forskolin response to control for changes in cell number per well from experiment to experiment. In agreement with previous studies, transfection of WT Gs resulted in a low level of basal cAMP while expression of Gs-R201H strongly increased the basal cAMP levels in the cells. While most of the mutations that suppressed the constitutively active GPA1-R297H had no effect on suppressing the human MAS mutation, three sites were identified that exhibited basal levels of cAMP significantly lower than those measured in cells expressing the MAS alleles: F142S, R231C, and L266T (Fig. 1b).

The ability of the three newly identified intragenic suppressors of R201H to support signaling through GPCRs was measured by cotransfecting cells with $2 \mu \mathrm{g}$ of plasmid encoding the human luteinizing hormone receptor (LHR) and $5 \mu \mathrm{g}$ of plasmid encoding one of the different isoforms of Gs, or empty vector. Protein expression was measured by western blot (Fig. 2a). Basal and hormone-stimulated levels of cAMP were measured for saturating concentrations of the LHR agonist hCG and reported as a percentage of the forskolin response (Fig. 2b). Cells expressing WT Gs exhibited a slight elevation in basal cAMP relative to cells transfected with the pCDNA3.1+ vector, and the acute response to high levels of hCG was unchanged. Expression of Gs-R201H produced a very high basal cAMP level that was not increased with hCG treatment. Other studies in our laboratory have demonstrated that transfection with lower concentrations of

Table $1 \mathrm{EC}_{50}(\mu \mathrm{M})$ and maximum responses (\% forskolin) for Gs alleles carrying $R 201 \mathrm{H}$ and intragenic suppressor mutations R231C, F142S, or L266T

\begin{tabular}{|c|c|c|c|c|c|}
\hline & Vector & WT & $\begin{array}{c}\text { R201H+ } \\
\text { R231C }\end{array}$ & $\begin{array}{r}\text { R201H }+ \\
\text { F142S }^{\mathrm{a}}\end{array}$ & $\begin{array}{l}\text { R201H+ } \\
\text { L266T }\end{array}$ \\
\hline$E C_{50}(\mu \mathrm{M})$ & 0.0526 & 0.179 & 0.878 & & 0.00867 \\
\hline $\begin{array}{l}E_{\max }(\% \text { forskolin } \\
\text { response) }\end{array}$ & 51.80 & 56.83 & $22.27 *$ & & 51.80 \\
\hline
\end{tabular}

Significantly different from WT, $P<0.05$, Student's $t$-test.

a Linear dose-response relationship precluded calculation of $\mathrm{EC}_{50}$ or $E_{\max }$ for this mutant.

Published by Bioscientifica Ltd. 
A
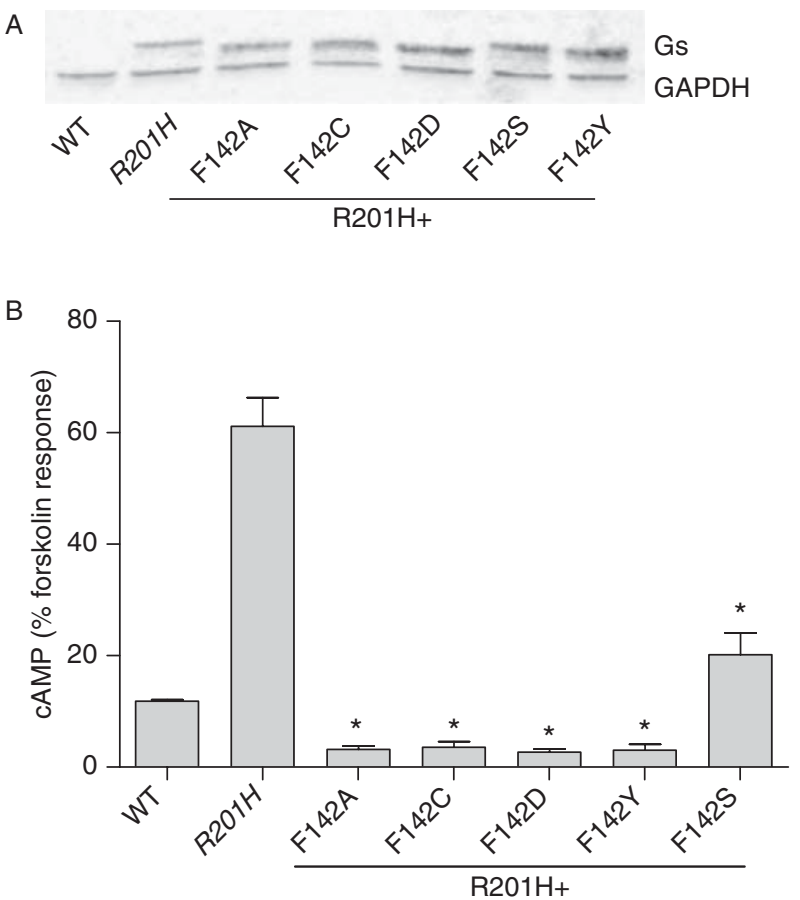

Figure 3

All mutations at $\mathrm{F} 142$ suppress the constitutive activity of $\mathrm{R} 201 \mathrm{H}$.

(A) Immunoblot of lysates from cells transfected with the various alleles of Gs probed for Gs and GAPDH. (B) Basal CAMP levels from cells transiently transfected with $5 \mu \mathrm{g}$ of plasmid encoding the indicated alleles of Gs. Bars represent the mean \pm S.E.M. for three to four independent experiments, each performed in duplicate. *Not different from WT basal CAMP, $P>0.05$.

Gs-R201H plasmid can produce an intermediate increase in basal cAMP that can be further increased with activation of the LHR by hCG (Tobar-Rubin et al. 2013). All three intragenic suppressors partially suppressed the response to hCG, with significant, about $50 \%$, reductions in cAMP relative to either WT-transfected or vectortransfected cells. Dose-response curves relating cAMP production to varying doses of hCG (Fig. 2c) showed that the $\mathrm{EC}_{50}$ for hCG was $0.05 \mathrm{U} / \mathrm{ml}$ for vector-transfected cells and $0.18 \mathrm{U} / \mathrm{ml}$ for WT-transfected cells, a difference that was not statistically significant when the averages of all experiments were analyzed together (Table 1 and Supplementary Table 2, see section on supplementary data given at the end of this article). The $\mathrm{EC}_{50}$ increased to $0.88 \mathrm{U} / \mathrm{ml}$ for $\mathrm{R} 201 \mathrm{H} / \mathrm{R} 231 \mathrm{C}$ and decreased to $0.01 \mathrm{U} / \mathrm{ml}$ for R201H/L266T. Only R201H/L266T exhibited a statistically significant change in the $\mathrm{EC}_{50}$ value $(\alpha=0.05)$. The maximum response to hormone was unchanged for R201H/L266T, but significantly decreased for R201H/ R231C $(\alpha=0.05)$ R201H/F142S-transfected cells showed a linear response to hCG, precluding the calculation of $\mathrm{EC}_{50}$ or $E_{\max }$.
The requirements for suppression of the $R 201 H$ mutation at each of these three sites of Gs were further explored by mutating the three different suppressors to a variety of other amino acids at each site. First, F142 was mutated to alanine, tyrosine, cysteine, and aspartic acid. Cells were transfected with Gs constructs carrying each of these substitutions at position F142 along with the R201H mutation. Protein expression was confirmed by western blot (Fig. 3a), and basal cAMP levels were measured as before. All of the substitutions examined strongly suppressed the $R 201 \mathrm{H}$ mutation to $3 \%$ of forskolin levels, which was even stronger than the original F142S mutation (Fig. 3b).

For $R 231$, the position was mutated to serine, alanine, isoleucine, glutamic acid, and lysine. Protein expression was again confirmed by western blot (Fig. 4a) and basal cAMP levels were measured (Fig. 4b). cAMP levels were not higher compared with WT $(8.2 \pm 3.5 \%$ of forskolin) for

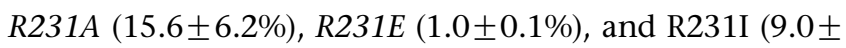
$0.9 \%)$, while R231S (32.9 $\pm 11.7 \%)$ and $R 231 K(36.6 \pm 7.9 \%)$
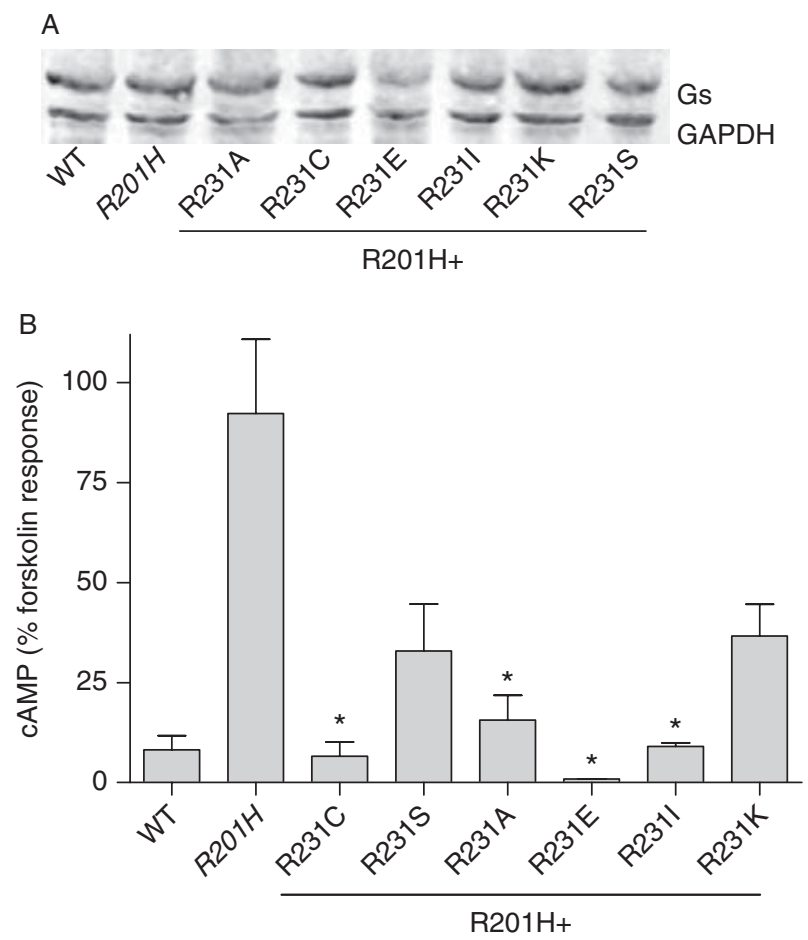

Figure 4

Several mutations at R231 suppress the constitutive activity of $R 201 \mathrm{H}$. (A) Immunoblot of lysates from cells transfected with the various alleles of Gs probed for Gs and GAPDH. (B) Basal cAMP levels from cells transiently transfected with $5 \mu \mathrm{g}$ of plasmid encoding the indicated alleles of Gs. Bars represent the mean \pm s.E.M. for four independent experiments, each carried out in duplicate. *Not different from WT basal CAMP, $P>0.05$.

Published by Bioscientifica Ltd. 
exhibited slightly elevated basal cAMP compared with WT, although still significantly lower than the original Gs- $R 201 H$ mutant. Some of the low cAMP for the R231E mutant may be attributed to its lower expression levels.

Finally, mutagenesis of L266 resulted in several intragenic suppressors that were even more effective than the originally isolated mutant L266T (Fig. 5b). Substitution to aspartic acid ( $1.3 \pm 0.4 \%$ of forskolin), asparagine $(7.5 \pm 0.4 \%)$, or serine $(6.7 \pm 2.8 \%)$ resulted in basal cAMP levels not different from WT $(5.3 \pm 1.9 \%)$. The conservative L266I mutation had no effect on suppressing the $R 201 \mathrm{H}$ mutation, producing basal cAMP levels of $39.3 \pm 5.7 \%$ of forskolin, not different from the $R 201 H$ alone at $49.7 \pm 14.4 \%$. Protein expression was confirmed by western blot (Fig. 5a), and the lower expression of L266D may contribute to its low basal cAMP levels.

If a drug was designed to mimic the effects of these intragenic suppressors on the $R 201 H$ mutation, it would also bind to the WT Gs expressed in the affected tissues. Thus, the effects of these intragenic suppressors in the absence of the $R 201 \mathrm{H}$ mutation are important to assess in order to wisely choose potential drug targets. For example,
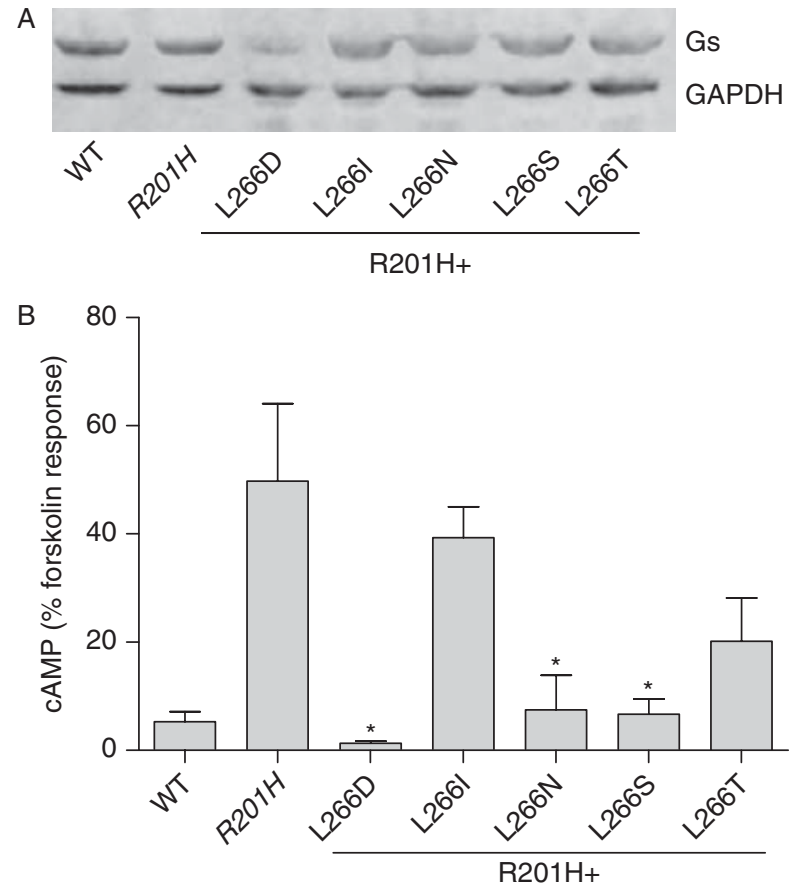

Figure 5

Several mutations at L266 suppress the constitutive activity of $R 201 \mathrm{H}$. (A) Immunoblot of lysates from cells transfected with the various alleles of Gs probed for Gs and GAPDH. (B) Basal cAMP levels from cells transiently transfected with $5 \mu \mathrm{g}$ of plasmid encoding the indicated alleles of Gs. Bars represent the mean \pm S.E.M. for three independent experiments, each carried out in duplicate. *Not different from WT basal CAMP, $P>0.05$. a pilot screen from our laboratory identified a suppressor that was constitutively active on its own (Tobar-Rubin et al. 2013), making that site a poor choice for drug targeting. Basal and hCG-stimulated cAMP production was measured in transfected cells expressing LHR and various mutant forms of Gs. Protein expression was confirmed by western blot (Fig. 6a). Suppressor alleles that exhibited basal cAMP levels closest to WT-transfected cells in previous experiments were chosen for these experiments. Gs isoforms carrying F142S, R231C, or L266N mutations again produced low levels of basal cAMP, and all were statistically indistinguishable from cells expressing WT Gs in their responses to maximal doses of hCG (Fig. 6b). The very low basal levels of cAMP in cells transfected with the mutant proteins were not due to inhibition of forskolin-stimulated cAMP, as the mass (pmol/well) of cAMP produced in the cells in response to forskolin was not different from the mass produced in cells transfected with WT Gs ( $P>0.2$, ANOVA). Dose-response relationships for cAMP production in the presence of varying concentrations of hCG were determined (Fig. 6c). The $\mathrm{EC}_{50}$ for hCG-stimulated cAMP production in all experiments combined was statistically unchanged from WT- or vector-transfected cells (Table 2 and Supplementary Table 3, see section on supplementary data given at the end of this article). R231C produced a significantly lower maximal response to hormone, while the others were unchanged from WT.

\section{Discussion}

A yeast mutagenesis system successfully identified three completely different amino acid substitutions that are each able to suppress the constitutive activity of the disease-associated $R 201 H$ mutation in Gs. These results reinforce the usefulness of yeast expression systems for large-scale random mutagenesis when asking questions relating the structure of a protein to its function (Apanovitch et al. 1998, Tobar-Rubin et al. 2013).

The three substitutions described in this paper are found in unique regions of Gs. R231, located on the Switch II helix, interacts via a salt bridge with E268, the Switch II backbone, and water molecules in the region of the GTP ligand's phosphates (Fig. 7A and D). This mutation's location is most similar to the location of our previously described intragenic suppressors, F222P/D223V (TobarRubin et al. 2013), which was also near the GTP-binding site and interacting with water molecules associated with GTP. Mutation of $R 231$ has been observed in patients with pseudohypoparathroidism type 1a (Farfel et al. 1996,

Published by Bioscientifica Ltd. 
A

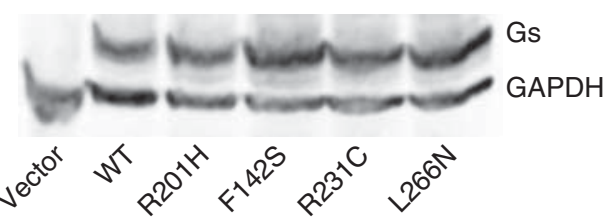

B

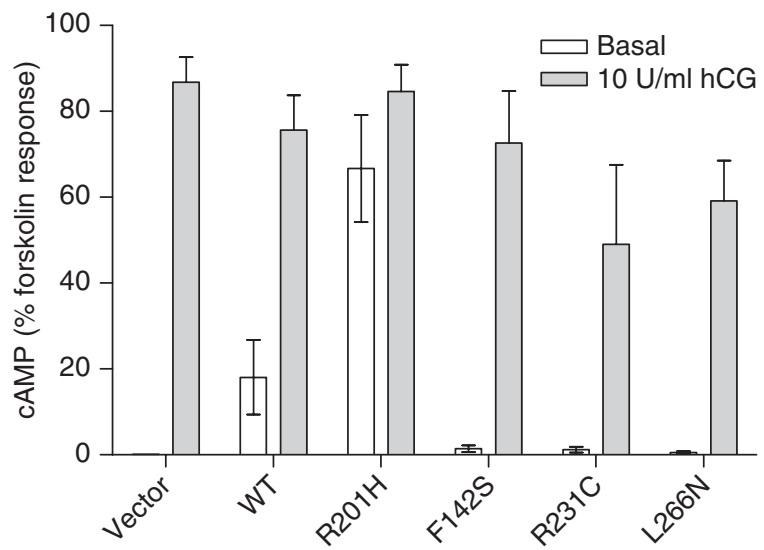

C

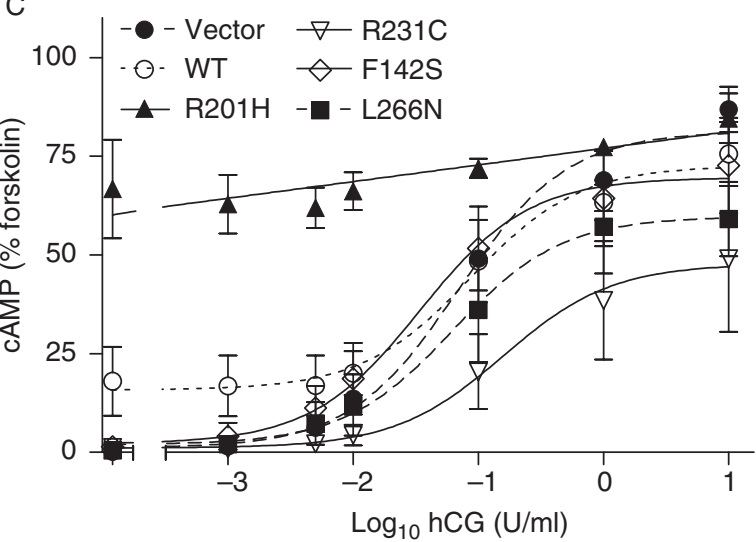

Figure 6

Mutation in the suppressor sites alone does not alter the ability of cells to respond to hormone. (A) Immunoblot of lysates from cells transfected with the indicated alleles of Gs probed for Gs and GAPDH. (B) Basal and maximallystimulated cAMP levels from (A) above. Data are the mean \pm s.E.M. for three independent experiments, each carried out in duplicate. The single mutants were not statistically different from WT in basal cAMP levels or CAMP levels produced in response to $10 \mathrm{U} / \mathrm{ml} \mathrm{hCG}$. (C) Dose-response curves for CAMP production in cells cotransfected with the human luteinizing hormone receptor (LHR) and the indicated alleles of Gs. Filled circles, vector; open circles, WT Gs; filled triangle, R201H; open down-pointing triangle, R231C; open diamond, F142S; and filled square, L266N. Points represent the mean \pm S.E.M. for three independent experiments, each performed in duplicate.

Ishikawa et al. 2001), and a mild impairment of cAMP accumulation was observed in HEK293 cells transiently transfected with an $R 231 \mathrm{H}$ allele of Gs (Farfel et al. 1996). In a follow-up study, the $R 231 \mathrm{H}$ mutation was shown to destabilize GTP binding, notably blocking activation of cAMP in response to cholera toxin (Iiri et al. 1997). These studies observed that $\mathrm{R} 231 \mathrm{H}$ proteins were ADP-ribosylated by cholera toxin, but were then unable to be activated by guanosine- $5^{\prime}-0^{\prime}$ (3-thio)triphosphate $(\mathrm{GTP} \gamma \mathrm{S})$. The activation defect was also observed in the presence of activated receptor and $\mathrm{AlF}_{4}^{-}$, and our results add a fourth activation mechanism that is blocked by $R 231$ mutation, mutation of $R 201$. The lower maximum response to hormone exhibited by $R 231$ mutants in our studies is consistent with these previous reports.

The other two suppressor mutations are hydrophobic residues that participate in hydrophobic interactions near Switch III (L266, Fig. 7B and E) or in the helical domain of the $\alpha$ subunit (F142, Fig. 7C and F). Loss of hydrophobic packing may destabilize the protein, exposing it to quality control by proteolysis. However, these protein isoforms are both expressed at levels equivalent to WT and R201H forms, suggesting that protein instability is not the primary source of suppression.

The mutations at F142 are particularly intriguing. Although less studied than the Ras-like domain, the helical domain has more recently been shown to participate in G protein signaling as well (Dohlman \& Jones 2012). The helical domain of Gi stabilizes nucleotide binding in the absence of $\mathrm{Mg}^{2+}$ (Coleman \& Sprang 1998), and in Gs undergoes large movements away from the Raslike domain in the structure of the heterotrimeric G-protein complexed with the agonist-occupied $\beta_{2}$ adrenergic receptor (Rasmussen et al. 2011). Notably, F142 and its hydrophobic packing partners F140 and F146 (Fig. 7F) are located in the $\alpha \mathrm{B}-\alpha \mathrm{C}$ loop (Switch IV), which is extended as the neighboring $\alpha \mathrm{B}$ helix unwinds by a quarter turn in Gi $\alpha_{1}$ activation. F142 in Gs is homologous to F118 in the Gi $\alpha_{1}$ structure, a residue that undergoes a major conformational shift from the interior of the loop in the inactive form to a solvent-exposed position in the GTP $\gamma$ S-bound form of $\mathrm{Gi}_{\alpha 1}$ (Mixon et al. 1995). Mutation of other residues in this loop of Gs decreased GDP release, GTP $\gamma$ S binding, and GTP hydrolysis (Echeverria et al. 2000).

Table $2 E_{50}(\mu \mathrm{M})$ and maximum responses (\% forskolin) for Gs alleles carrying only intragenic suppressor mutations $R 231 \mathrm{C}$, F142S, or L266T. $n=3$ independent experiments

\begin{tabular}{|c|c|c|c|c|c|}
\hline & Vector & WT & R231C & F142S & L266N \\
\hline $\mathrm{EC}_{50}(\mu \mathrm{M})$ & 0.0693 & 0.0870 & 0.158 & 0.0340 & 0.0622 \\
\hline $\begin{array}{c}E_{\max }(\% \text { forskolin } \\
\text { response) }\end{array}$ & 81.28 & 72.61 & $47.74^{*}$ & 69.59 & 59.67 \\
\hline
\end{tabular}

*Significantly less than WT, $P<0.05$, Student's $t$-test.

Published by Bioscientifica Ltd. 
A

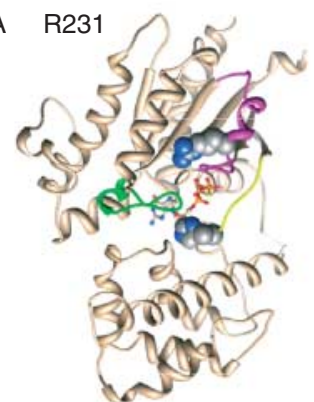

D

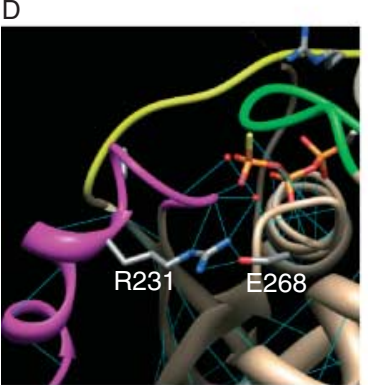

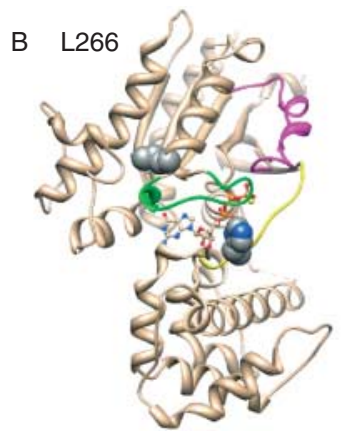

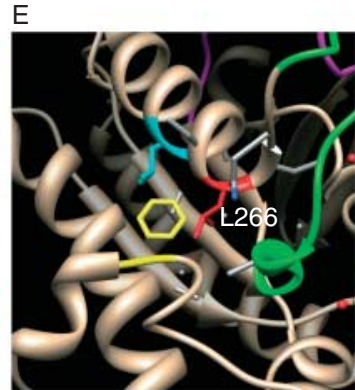

C $\quad \mathrm{F} 142$
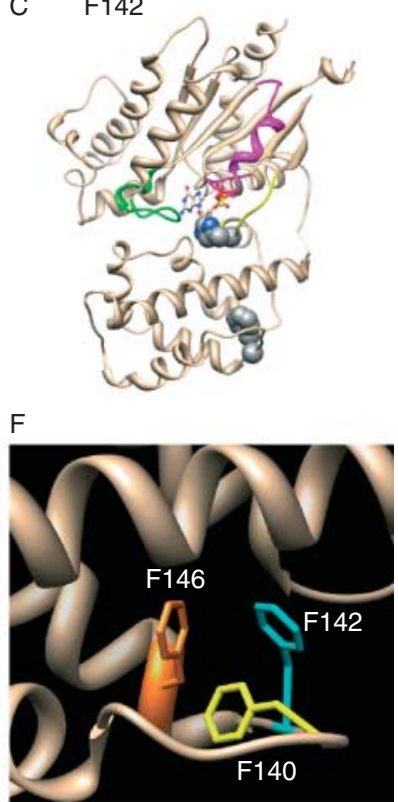

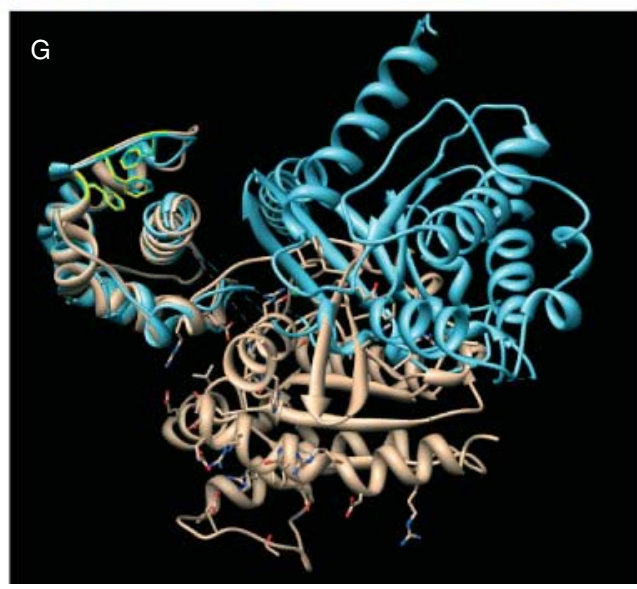

\section{Figure 7}

The locations of the three suppressor mutations are modeled on the GTP $\gamma \mathrm{S}$ bound structure of Gs (AZT1) using Chimera Software (University of California, San Francisco, CA, USA). (A, B and C) Structures of the entire Gs protein. Switch 1 is yellow, Switch II is pink, and Switch III is green. The nucleotide is shown as ball-and-stick; R201H and the indicated suppressor sites are shown in space-fill. The structures are rotated slightly left to right in ( $A, B$ and $C$ ) to provide better visualization of the location of each suppressor mutation. (D, E and F) Closeups of the local region of each suppressor mutation. (D) Interaction of Arg231 with other residues in the Ras-like domain. Hydrogen bonds are indicated in blue. Arg231 is shown colored by atom, extending from left to right from the Switch II helix. Arg231 forms a salt bridge with Glu268 (also shown colored by atom). Arg231 also hydrogen bonds to the backbone of Switch II and a water molecule. (E) Interaction of Leu266 with other amino acids in the Ras-like domain. Leu266 is shown in

Interestingly, the crystal structure of GTP $\gamma$ S-bound Gs shows F142 packed rather than exposed to solvent (Sunahara et al. 1997), as does the structure of nucleotide-free Gs- $\beta \gamma-\beta_{2} A R$ (Rasmussen et al. 2011). Alignment of red, Leu270 in blue, and Phe312 is yellow (not all atoms were mapped on the structure for Phe312). These three residues pack with hydrophobic interactions in the core of the Ras-like domain of Gs. (F) Interactions of Phe142 with other residues in the helical domain. Phe142 is colored blue; Phe140 is colored yellow, and Phe146 is colored orange form a hydrophobic triad with Phe142. (G) Alignment of the helical domains of GTP $\gamma$ S-bound Gs (1AZT) and nucleotide-free Gs (3SN6). The blue chain represents the GTP $\gamma$ Sbound structure, with cyan residues showing the cluster of three phenylalanine residue side chains in the helical domain. The nucleotide-free structure is colored tan, with phenylalanine side chains in the helical domain colored yellow. The helical domain is to the left on the figure, showing little change in the conformations of the two protein states. The Ras-like domain is on the right of the figure, showing the large rotation of this domain relative to the helical domain in the two structures.

the helical domains of these two Gs structures shows almost no difference in the arrangement of the three phenylalanine residues in this region, even though the helical domain itself makes a large displacement

Published by Bioscientifica Ltd. 
away from the Ras-like domain in the nucleotide-free conformation (Fig. 7G).

Several other missense mutations in Gs have been associated with hormone resistance in psuedohypoparathyroidism type 1A; L99P, P115L, C162R, R231H, S250R, $R 258 W, R 258 A, Q 170 A$, and $A 366 S$ have all been reported as reducing Gs activity in these patients (MIM \#103580). Similar to the mutations identified in our suppressor screen, these residues are scattered throughout the tertiary structure of Gs. Several of them (L99P, P115L, and C162R) are in the helical domain, such as the F142 suppressors reported in this paper, while another set is part of or near switch III (Q170A, S250R, and R258W), akin to the L266 site. Identification of these types of mutations in the far more complex human organismal context gives credence to our hypothesis that manipulation of the sites identified in this report may be beneficial in systems beyond simple cell culture models. Investigation of the effects of these identified suppressor sites on other alleles associated with MAS (R201C and R201S) and other constitutively active Gs alleles $(Q 227 L)$ will be important follow-up studies.

The relatively high false-positive rate of identifying suppressor mutations in the yeast $\mathrm{G} \alpha$ subunit that did not suppress the constitutive activity of the R201H human Gs protein is somewhat surprising, particularly given the strong conservation of GTP-binding proteins throughout evolution. The lack of efficacy for many of the mutations identified in the yeast Gpa1 system may suggest that mutations that were successful in suppression of constitutively active Gs may be more broadly effective in suppression of any constitutively active $\alpha$ subunit or other activating mutations in Gs, a hypothesis that is currently under investigation in our laboratory as other $\alpha$ subunit activating mutations have been linked to a variety of human diseases (Landis et al. 1989, Clementi et al. 1990, Lyons et al. 1990, Lania et al. 2006).

\section{Supplementary data}

This is linked to the online version of the paper at http://dx.doi.org/10.1530/ JME-13-0297.

\section{Declaration of interest}

The authors declare that there is no conflict of interest that could be perceived as prejudicing the impartiality of the research reported.

\section{Funding}

This work was supported by National Institutes of Health National Institute of Dental and Craniofacial Research (grant number 1R15DE020190-01) to R P-R.

http://jme.endocrinology-journals.org DOI: 10.1530/JME-13-0297
() 2014 Society for Endocrinology Printed in Great Britain

\section{Author contribution statement}

$R$ P-R participated in research design. $R$ P-R, R T-R, D J, K T, J C, and R A conducted experiments. R P-R, R T-R, D J, K T, J C, R A, and J H contributed new reagents or analytic tools. $R$ P-R, R T-R, D J, K T, J C, and R A performed data analysis. $\mathrm{R}$ P-R and $\mathrm{J} H$ contributed to the writing of the manuscript.

\section{References}

Albright F, Butler AM, Hampton AO \& Smith P 1937 Syndrome characterized by osteitis fibrosa disseminate, areas of pigmentation, and endocrine dysfunction, with precocious puberty in females: report of 4 cases. New England Journal of Medicine 216 727-746. (doi:10.1056/ NEJM193704292161701)

Apanovitch DM, Iiri T, Karasawa T, Bourne HR \& Dohlman HG 1998 Second site suppressor mutations of a GTPase-deficient G-protein $\alpha$-subunit. Selective inhibition of G $\beta \gamma$-mediated signaling. Journal of Biological Chemistry 273 28597-28602. (doi:10.1074/jbc.273.44.28597)

Candeliere GA, Roughley PJ \& Glorieux FH 1997 Polymerase chain reaction-based technique for the selective enrichment and analysis of mosaic arg201 mutations in Gas from patients with fibrous dysplasia of bone. Bone 21 201-206. (doi:10.1016/S8756-3282(97)00107-5)

Chan B \& Zacharin M 2006 Pamidronate treatment of polyostotic fibrous dysplasia: failure to prevent expansion of dysplastic lesions during childhood. Journal of Pediatric Endocrinology \& Metabolism 19 75-80. (doi:10.1515/JPEM.2006.19.1.75)

Chen P, Johnson P, Sommer T, Jentsch S \& Hochstrasser M 1993 Multiple ubiquitin-conjugating enzymes participate in the in vivo degradation of the yeast MAT $\alpha 2$ repressor. Cell 74 357-369. (doi:10.1016/00928674(93)90426-Q)

Clementi E, Malgaretti N, Meldolesi J \& Taramelli R 1990 A new constitutively activating mutation of the Gs protein $\alpha$ subunit gsp oncogene is found in human pituitary tumours. Oncogene 5 1059-1061.

Coleman DE \& Sprang SR 1998 Crystal structures of the G protein Gi $\alpha 1$ complexed with GCP and $\mathrm{Mg}^{2+}$ : a crystallographic titration experiment. Biochemistry 37 14376-14385. (doi:10.1021/bi9810306)

Collins MT 2006 Spectrum and natural history of fibrous dysplasia of bone,. Journal of Bone and Mineral Research 21 (Suppl 2) P99-P104. (doi:10. 1359/jbmr.06s219)

Dohlman HG \& Jones JC 2012 Signal activation and inactivation by the G $\alpha$ helical domain: a long-neglected partner in G protein signaling. Science Signaling 5 re2. (doi:10.1126/scisignal.2003013)

Dumitrescu CE \& Collins MT 2008 McCune-Albright syndrome. Orphanet Journal of Rare Diseases 3 12. (doi:10.1186/1750-1172-3-12)

Echeverria V, Hinrichs MV, Torrejon M, Ropero S, Martinez J, Toro MJ \& Olate J 2000 Mutagenesis in the switch IV of the helical domain of the human Gs $\alpha$ reduces Its GDP/GTP exchange rate. Journal of Cellular Biochemistry 76 368-375. (doi:10.1002/(SICI)1097-4644(20000301) 76:3<368::AID-JCB4>3.0.CO;2-B)

Eugster EA, Rubin SD, Reiter EO, Plourde P, Jou HC \& Pescovitz OH 2003 Tamoxifen treatment for precocious puberty in McCune-Albright syndrome: a multicenter trial. Journal of Pediatrics 143 60-66. (doi:10.1016/S0022-3476(03)00128-8)

Farfel Z, Iiri T, Shapira H, Roitman A, Mouallem M \& Bourne HR 1996 Pseudohypoparathyroidism, a novel mutation in the $\beta / \gamma$-contact region of Gs- $\alpha$ impairs receptor stimulation. Journal of Biological Chemistry 271 19653-19655. (doi:10.1074/jbc.271.33.19653)

Feuillan P, Calis K, Hill S, Shawker T, Robey PG \& Collins MT 2007 Letrozole treatment of precocious puberty in girls with the McCuneAlbright syndrome: a pilot study. Journal of Clinical Endocrinology and Metabolism 92 2100-2106. (doi:10.1210/jc.2006-2350)

Iiri T, Farfel Z \& Bourne HR 1997 Conditional activation defect of a human Gs- $\alpha$ mutant. PNAS 94 5656-5661. (doi:10.1073/pnas.94.11.5656)

Ishikawa Y, Tajima T, Nakae J, Nagashima T, Satoh K, Okuhara K \& Fujieda K 2001 Two mutations of the Gs- $\alpha$ gene in two Japanese patients with 
sporadic pseudohypoparathyroidism type Ia. Journal of Human Genetics 46 426-430. (doi:10.1007/s100380170062)

Landis C, Masters SB, Spada A, Pace AM, Bourne HR \& Vallar L 1989 GTPase inhibiting mutations activate the $\alpha$ chain of Gs and stimulate adenylyl cyclase in human pituitary tumors. Nature 340 692-696. (doi:10.1038/ 340692a0)

Lania AG, Mantonvani G \& Spada A 2006 Mechanisms of disease: mutations of $G$ proteins and G-protein coupled receptors in endocrine diseases. Nature Clinical Practice. Endocrinology \& Metabolism 2 681-691. (doi:10.1038/ncpendmet0324)

Liens D, Delmas PD \& Meunier PJ 1994 Long-term effects of intravenous pamidronate in fibrous dysplasia of bone. Lancet 343 953-954. (doi:10.1016/S0140-6736(94)90069-8)

Lumbroso S, Paris F \& Sultan C 2004 Activating Gs- $\alpha$ mutations: analysis of 113 patients with signs of McCune-Albright syndrome - a European collaborative study. Journal of Clinical Endocrinology and Metabolism $\mathbf{8 9}$ 2107-2113. (doi:10.1210/jc.2003-031225)

Lyons J, Landis CA, Harsh G, Vallar L, Grunwald K, Feichtinger H, Duh Q-Y, Clark OH, Kawasaki E, Bourne HR et al. 1990 Two G protein oncogenes in human endocrine tumors. Science 249 655-659. (doi:10.1126/ science.2116665)

McCune DJ 1936 Osteitis fibrosa cystic: the case of a nine-year-old girl who also exhibits precocious puberty, multiple pigmentation of the skin and hyperthyroidism. American Journal of Diseases of Children 36 743-744.

Medici R, Bianchi E, Di Segni G \& Tocchini-Valentini GP 1997 Efficient signal transduction by a chimeric yeast-mammalian $G$ protein $\alpha$ subunit Gpa1-Gs $\alpha$ covalently fused to the yeast receptor Ste2. EMBO Journal 16 7241-7249. (doi:10.1093/emboj/16.24.7241)

Mixon MB, Lee E, Coleman DE, Berghuis AM, Gilman AG \& Sprang SR 1995 Tertiary and quaternary structural changes in Gi $\alpha 1$ induced by GTP hydrolysis. Science 270 954-960. (doi:10.1126/science.270.5238.954)

Mumberg D, Müller R \& Funk M 1995 Yeast vectors for the controlled expression of heterologous proteins in different genetic backgrounds. Gene 156 119-122. (doi:10.1016/0378-1119(95)00037-7)

Ooms LS, Koster MJ, Mitchell JR \& Pals-Rylaarsdam R 2006 Identification of a second-site suppressor mutation of the GTPase defect associated with McCune-Albright syndrome: a mode using the yeast heterotrimeric
G protein, GPA1. Archives of Physiology and Biochemistry 112 116-173. (doi:10.1080/13813450600935271)

Plotkin H, Rauch F, Zeitlin L, Munns C, Travers R \& Glorieux FH 2003 Effect of pamidronate treatment in children with polyostotic fibrous dysplasia of bone. Journal of Clinical Endocrinology and Metabolism $\mathbf{8 8}$ 4569-4575. (doi:10.1210/jc.2003-030050)

Rasmussen SG, DeVree BT, Zou Y, Kruse AC, Chung KY, Kobilka TS, Thian FS, Chae PS, Pardon E, Calinski D et al. 2011 Crystal structure of the $\beta 2$ adrenergic receptor-Gs protein complex. Nature 477 549-555. (doi:10.1038/nature10361)

Riminucci M, Fisher LW, Majolagbe A, Corsi A, Lala R, de Sanctis C, Robey PG \& Bianco P 1999 A novel GNAS1 mutation, R201G, in McCuneAlbright syndrome. Journal of Bone and Mineral Research 14 1987-1989. (doi:10.1359/jbmr.1999.14.11.1987)

Schwindinger WF, Francomano CA \& Levine MA 1992 Identification of a mutation in the gene encoding the $\alpha$ subunit of the stimulatory G-protein of adenylyl cyclase in McCune-Albright syndrome. PNAS 89 5152-5156. (doi:10.1073/pnas.89.11.5152)

Stanton RP, Ippolito E, Springfield D, Lindaman L, Wientroub S \& Leet A 2012 The surgical management of fibrous dysplasia of bone. Orphanet Journal of Rare Diseases 7 (Suppl 1) S1. (doi:10.1186/17501172-7-S1-S1)

Sunahara RK, Tesmer JJ, Gilman AG \& Sprang SR 1997 Crystal structure of the adenylyl cyclase activator Gs $\alpha$. Science 278 1943-1947. (doi:10.1126/science.278.5345.1943)

Tesmer JJ, Sunahara RK, Gilman AG \& Sprang SR 1997 Crystal structure of the catalytic domains of adenylyl cyclase in a complex with $\mathrm{G}_{\mathrm{s} \alpha}-\mathrm{GTP} \gamma \mathrm{S}$. Science 278 1907-1916. (doi:10.1126/science.278. 5345.1907)

Tobar-Rubin R, Sultan D, Janevska D, Turcic K, Carroll J \& Pals-Rylaarsdam R 2013 Intragenic suppression of a constitutively active allele of Gs $\alpha$ associated with McCune-Albright syndrome. Journal of Molecular Endocrinology 50 193-201. (doi:10.1530/JME-12-0087)

Weinstein LS, Shenker A, Gejman PV, Merino MJ, Friedman E \& Spiegel AM 1991 Activating mutations of the stimulatory G protein in the McCune-Albright syndrome. New England Journal of Medicine 325 1688-1695. (doi:10.1056/NEJM199112123252403)

Received in final form 5 March 2014

Accepted 17 March 2014 http://jme.endocrinology-journals.org DOI: 10.1530/JME-13-0297 (c) 2014 Society for Endocrinology Printed in Great Britain 